\title{
FORMAÇÃO DE PROFESSORES DE LÍNGUA PARA A AUTONOMIA: O BURACO É MAIS EMBAIXO
}

\section{LANGUAGE TEACHERS EDUCATION TOWARDS AUTONOMY: A FURTHER AND DEEPER MATTER}

\section{David José de Andrade Silva*}

\begin{abstract}
RESUMO
A formação de professores de língua tem fomentado discussões no campo teórico em vários aspectos. Dentre eles, a questão da construção de projetos pedagógicos de curso (PPC) que propiciem aos discentes desenvolverem capacidade de estudo autônomo e independente, na expectativa de que promovam práticas pedagógicas rumo à autonomia em suas futuras salas de aula. $\mathrm{O}$ presente artigo apresentará a gênese dos cursos de licenciatura no Brasil desde o período imperial até a atualidade; discutirá os entraves históricos que dificultam nos cursos de Letras a inovação de seus currículos; e proporá algumas possibilidades de superação da atual conjuntura. O objetivo não é o de oferecer uma solução, mas de ampliar o debate para o pano de fundo da questão. A metodologia adotada é a pesquisa bibliográfica e apoiarse-á nos trabalhos de Benson (2006), Chitashvili (2007), Smith (s/d), Aoki (2000) e Leffa (2003), no conceito de autonomia discente e docente; Gatti $(2009,2010)$, na investigação dos PPC e do perfil dos cursos de Letras-Português no Brasil; Paiva (2003, 2004, 2005), no estudo da história dos cursos de Letras-Inglês; Masetto (2003-2004, 2011) e Cunha (2003), na inovação curricular no ensino superior.
\end{abstract}

Palavras-chave: autonomia; formação de professores; inovação curricular.

\section{ABSTRACT}

Language teacher education has raised theoretical debates on several aspects. One of them is the conception of undergraduate curriculum, which should allow students to develop autonomous and independent study skills so that they would become professionals to educate towards autonomy. The present work aims at presenting a historical perspective of the undergraduate teacher education in Brazil from the imperial times to the present day; at arguing on the historical setbacks which make it hard for undergraduate language degree programs to innovate in their curricula; and also at suggesting some possibilities to overcome the current drawbacks. This study main goal is not to offer solutions, but to broaden the discussion in order to provide background to the discussion. This study is based on bibliographic research, as well as on theoretical ideas developed by Benson (2006), Chitashvili (2007), Smith (s/d), Aoki (2000) and Leffa (2003), on the concept of student and teacher autonomy; Gatti $(2009,2010)$, on the investigation of the profile and

\footnotetext{
*UFPR, Paraná (PR), Brasil. dajoas@gmail.com
} 
the curricula of the undergraduate Portuguese language courses in Brazil; Paiva (2003, 2004, 2005), on the history study of the undergraduate English language courses; and lastly by Masetto (2003-2004, 2011) and Cunha (2003), on higher education curriculum innovation. Keywords: autonomy; teacher education; curricular innovation.

\section{CONSIDERAÇÕES INICIAIS}

A expressão popular que compõe o título do presente trabalho tem o objetivo de problematizar a almejada formação de professores autônomos à luz da história das licenciaturas no Brasil, das legislações recentes e dos caminhos curriculares possíveis de serem trilhados.

Em 1996, com a promulgação da Lei de Diretrizes e Bases da Educação Nacional (LDBEN - Lei nº.394 de 20 de dezembro de 1996, doravante LDB), o artigo 87 instituiu a "Década da Educação" como um marco para as instituições diretamente envolvidas no processo que se desenhava: as escolas, onde os professores sem formação superior teriam que se adaptar às novas exigências legais para continuarem exercendo a profissão; e as instituições de ensino superior (doravante IES) que, além de se reconfigurarem administrativamente, deveriam se preparar, frente às mudanças estruturais na organização educacional, para receber o contingente de professores em serviço do caso anteriormente citado e também estudantes em formação inicial. Independentemente de o licenciando estar na primeira ou na segunda situação, o perfil de docente esperado na sala de aula havia mudado a partir da 9.394/96.

O artigo 13 da LDB apresenta o rol de atribuições do profissional do magistério e insere, ainda que já houvesse iniciativas particulares de alguns, os incisos I e VI, que tratam respectivamente da participação efetiva dos professores na elaboração da proposta pedagógica da escola e são agentes articuladores da escola com a família e a comunidade escolar. Percebe-se, então, que os docentes passaram de meros executores do projeto pedagógico a corresponsáveis, além de ter sido repaginada a figura do professor que conversava com os familiares somente nas reuniões de pais e mestres para um agente de interlocução com a comunidade escolar, tão importante quanto os demais componentes da direção e equipe pedagógica. Essa nova visão do papel docente, registrada na lei, aparenta uma conquista da categoria, que ganha um status de protagonista, mas ainda faltavam subsídios para o direcionamento que os cursos de licenciatura deveriam seguir para atingir os objetivos almejados e efetivamente promoverem uma década qualitativa da educação. 
A Câmara de Educação Superior do Conselho Nacional de Educação (doravante CES e CNE, respectivamente) elaborou o Parecer ${ }^{1} n^{\circ} 776 / 97$, aprovado em 3 de dezembro de 1997 (ou seja, quase um ano após a LDB) com orientações para as diretrizes curriculares dos cursos de graduação, que até então não seguiam parâmetros básicos e geravam discrepâncias curriculares entre as IES. Segundo o Parecer CNE/CES n 583/2001 de 4 de abril de 2001, a Secretaria de Ensino Superior (SESu) do Ministério da Educação (MEC) recebeu aproximadamente 1200 propostas de diretrizes "bastante heterogêneas" para serem sistematizadas, variando a duração e a carga horária, respectivamente, de 4 a 12 semestres e de 2.000 a 6.800 horas. O documento visava promover mudanças na construção dos projetos pedagógicos para adequar a formação universitária às necessidades sociais exógenas e não como retroalimentação exclusivamente endógena à academia. Mas a tarefa não seria fácil, pois a universidade constituiu-se paradoxalmente como espaço de diversidade ideológico-discursiva e de conservadorismo e rigidez pedagógica: todo e qualquer movimento de alteração do status quo era (ou ainda é?) visto como uma ameaça, que deveria ser combatido e eliminado.

Os aspectos destacados pelos relatores do Parecer $n^{\circ} 776 / 97$ para direcionar a construção e a flexibilização dos currículos, e consequentemente servir como contribuição preliminar para a formação de professores, são os seguintes:

1) Assegurar, às instituições de ensino superior, ampla liberdade na composição da carga horária a ser cumprida para a integralização dos currículos, assim como na especificação das unidades de estudos a serem ministradas;

2) Indicar os tópicos ou campos de estudo e demais experiências de ensinoaprendizagem que comporão os currículos, evitando ao máximo a fixação de conteúdos específicos com cargas horárias pré-determinadas, as quais não poderão exceder $50 \%$ da carga horária total dos cursos;

3) Evitar o prolongamento desnecessário da duração dos cursos de graduação;

4) Incentivar uma sólida formação geral, necessária para que o futuro graduado possa vir a superar os desafios de renovadas condições de exercício profissional e de produção do conhecimento, permitindo variados tipos de formação e habilitações diferenciadas em um mesmo programa;

5) Estimular práticas de estudos independente, visando uma progressiva autonomia profissional e intelectual do aluno;

\footnotetext{
1 Trabalharemos aqui com os Pareceres em vez das Resoluções, porque os primeiros são documentos que dão a sustentação teórico-metodológica e conceitual dos cursos para os segundos, que são atos normativos.
} 
6) Encorajar o reconhecimento de habilidades, competências e conhecimentos adquiridos fora do ambiente escolar, inclusive os que se refiram à experiência profissional julgada relevante para a área de formação considerada;

7) Fortalecer a articulação da teoria com a prática, valorizando a pesquisa individual e coletiva, assim como os estágios e a participação em atividades de extensão.

8) Incluir orientações para a condução de avaliações periódicas que utilizem instrumentos variados e sirvam para informar a docentes e a discentes acerca do desenvolvimento das atividades didáticas.

É latente, nesses oito aspectos, a busca por um modelo de educação superior que supere a morosidade e a inércia e consiga acompanhar as transformações sociais na mesma velocidade de transmissão de dados do mundo virtual. Assim, as IES, cujo modelo pedagógico ainda ignore a revolução tecnológica e social e não dê vazão à autonomia discente, caminham de encontro, no âmbito legal, aos preceitos defendidos pelos conselheiros da CES.

Ao mesmo tempo, não podemos negar a presença de elementos a serviço do neoliberalismo que permeiam os mesmos tópicos, principalmente por servirem de base para a descontrolada, oportunista, mercadológica e desqualificada expansão de licenciaturas no mesmo período. Por exemplo, a questão do prolongamento desnecessário e do destaque para a formação generalista pode ser vista como uma forma de sucatear e empobrecer teoricamente a universidade como produtora de conhecimento para privilegiar o mercado: o país não precisaria de sujeitos críticos, mas de mão de obra operacional.

No ano de 2001, ocorreu um fenômeno peculiar. Enquanto o Parecer $n^{\circ} 009 / 2001$ de 8 de maio aprovado pelo pleno (CP) do CNE instituía as Diretrizes Curriculares Nacionais para a Formação de Professores da Educação Básica, com o objetivo de concretizar o perfil protagonista e autônomo do docente visto na LDB e no Parecer 776/97 e desvinculá-lo da lógica do " $3+1$ " como apêndice dos bacharelados, a CES aprovou o Parecer 492/2001 no dia 03 de abril as Diretrizes Curriculares Nacionais dos cursos de Filosofia, História, Geografia e Letras. Ou seja, os cursos responsáveis por quase metade das disciplinas ofertadas na Educação Básica (doravante EB) tiveram suas diretrizes aprovadas um mês antes de poder inserir as especificidades do magistério no bojo do documento.

As graduações que teoricamente teriam a oportunidade de contemplar elementos de formação de professores seriam, em ordem cronológica: Ciências Biológicas (Parecer CNE/CES n 1301 de 06 de novembro de 2001); Matemática 
(Parecer CNE/CES n¹302/2001 de 6 de novembro de 2001); Química (Parecer CNE/CES n¹303 de 6 de novembro de 2001); Física (Parecer CNE/CES n 1304 de 6 de novembro de 2001); Educação Física (Parecer CNE/CES n¹38 de 3 de abril de 2002); Pedagogia (Parecer CNE/CES n`5 de 13 de dezembro de 2005); Artes Visuais (Parecer CNE/CES n²89/2007 de 6 de dezembro de 2007). É visível que a elaboração dos pareceres fez-se em três blocos: o primeiro, que antecedeu o Parecer 09/2001, abarcou a maioria dos cursos relacionados às Ciências Humanas e Letras; o segundo, aprovado seis meses depois, envolvendo as Ciências Naturais; e o terceiro, onde se inserem cursos que tiveram de um a seis anos para amadurecer a concepção de suas respectivas licenciaturas.

Levando-se em conta que o primeiro e segundo blocos correspondem a praticamente oitenta por cento das disciplinas das séries finais do Ensino Fundamental (doravante EF) e Ensino Médio (doravante EM), faz-se necessário ponderar sobre algumas questões em relação aos critérios do MEC quanto às licenciaturas: seria pressa em fornecer às IES subsídios para implantar os projetos pedagógicos de curso (doravante PPC) nos moldes do Parecer 776/97? Ou o CNE considerava o prazo de discussão após o Parecer 776/97 (quatro anos) suficiente para mudar cursos de mais de meio século? Não nos cabe responder a essas perguntas, mas devemos avaliar os efeitos de diretrizes curriculares de cursos de natureza distinta (bacharelado e licenciatura) sendo instauradas sem a devida observação dos preceitos que norteiam a legislação, para não incorrer em focar no legalismo em vez das discussões de fundo que embasam a lei.

Nosso interesse neste artigo é discutir os pressupostos e implicações da possibilidade de implantação do aspecto 5 do Parecer n ${ }^{\circ} 776 / 97$ - estimular práticas de estudos independentes, visando uma progressiva autonomia profissional e intelectual do aluno - na graduação em Letras. Para isso, consideraremos os seguintes parâmetros: situar as discussões sobre autonomia na licenciatura; indicadores sobre o estado da arte das graduações em Letras no Brasil; e a inserção de elementos inovadores no projeto pedagógico como alternativa para ressignificar o papel do curso e de professores em formação na sociedade.

Destacamos que serão abordadas as graduações em Letras de forma genérica, pois os cursos possuem grades praticamente "espelhadas", modificando apenas a habilitação correspondente (vernáculas ou estrangeiras) sem alterações significativas na estrutura, no caso das licenciaturas únicas, uma vez que as duplas ainda possuem problemas de desequilíbrio de carga horária em favor da Língua Portuguesa (PAIVA, 2005). 


\title{
1. UM POUCO SOBRE A AUTONOMIA
}

A pesquisa sobre autonomia na área de línguas tem crescido consideravelmente no mundo acadêmico. Benson (2006) contabilizou que do ano 2000 a 2006, em termos quantitativos, já havia mais trabalhos publicados do que nos 25 anos anteriores. A seguir, veremos algumas concepções.

Holec (1981 apud Benson, 2006, p.22) definiu a autonomia como "a habilidade de responsabilizar-se por seu próprio aprendizado". Para Dickinson (1987, p.11 apud Benson, 2006, p.22), seria "a situação na qual o aprendiz é totalmente responsável por todas as decisões relacionadas à sua aprendizagem e à implementação das decisões". Em Little (1991 apud Benson, 2006, p.22), levanta-se a questão de quais seriam os componentes mais importantes da autonomia na aprendizagem de língua ao colocar que esta "depende do desenvolvimento e exercício de uma capacidade de distanciamento, reflexão crítica, tomada de decisão e ação independente". Chitashvili $(2007$, p.17) tenta abranger a amplitude do conceito nos seguintes termos:

\begin{abstract}
Autonomia é um sistema socio-cognitivo complexo, manifestado em diferentes graus de independência e controle de um sujeito sobre seu processo de aprendizado, envolvendo capacidades, habilidades, atitudes, vontade, tomada de decisão, escolhas, planejamento, ações, e avaliação tanto como um aprendiz de língua quanto como um comunicador dentro ou fora da sala de aula. Como um sistema complexo, é dinâmico, caótico, imprevisível, não-linear, adaptativo, aberto, auto-organizado e sensível às condições iniciais e feedback².
\end{abstract}

A intenção inicial de estudar a autonomia do aprendiz despertou o interesse em pesquisar os professores. Aoki (2000, apud SMITH, p.2) definiu a autonomia docente como "a capacidade, liberdade, e/ou responsabilidade de um sujeito de fazer escolhas em relação ao ensino". E como seria a formação inicial para o magistério que contemplasse esses requisitos e ainda considerasse os estudantes?

Smith (s/d, p. 6) propõe a adoção de uma "pedagogia para a autonomia de professores em formação", cujas características são (SMITH, s/d): acompanhamento das pesquisas sobre a autonomia de estudantes e buscar trazer as experiências interessantes para a licenciatura; consciência de que é um processo de aprendizagem contínuo ao longo da vida; engajamento dos estudantes na reflexão crítica sobre os objetivos, conteúdos e processos de sua aprendizagem, melhoria das habilidades

2 Mantivemos a palavra feedback do original em inglês por não encontrar um sinônimo em português com o mesmo sentido. As traduções não referenciadas são de nossa responsabilidade. 
discentes para aprender durante a prática docente no campo de estágio. Na mesma perspectiva, Fontana (2009, p.2007) também destaca que são fatores inerentes ao comportamento autônomo "a conscientização, o desenvolvimento de competências e de senso crítico, requisitos para o estabelecimento de objetivos, a tomada de decisões e a avaliação".

Por outro lado, Leffa (2003) tem um posicionamento radical sobre a questão e advoga que as instituições educacionais (incluindo o ensino superior) devem oferecer condições para o discente desenvolver a autonomia (LEFFA, 2003, p.46):

\footnotetext{
(...) a solução me parece é que a escola passe a fazer menos, idealmente, que não faça nada. Deixe o aluno aprender sozinho. Coloque um recurso aqui, outro recurso lá, disponibilize alguns professores, mas não atrapalhe a aprendizagem do aluno.
}

Independentemente das concepções e propostas de encaminhamento apresentadas, concordo com Smith (s/d) que é preciso olharmos para dentro das graduações e, principalmente, para os professores formadores, no sentido de discernir o que é modismo e o que realmente pode contribuir para a formação discente. Além disso, institucionalmente são esses os sujeitos com poder para mudar suas próprias práticas em sala e também propor alterações nos projetos pedagógicos. No entanto, veremos na sequência que o histórico dos cursos de Letras é complexo e sua estagnação não é aleatória, mas faz parte de um conjunto de medidas que deterioram a educação há décadas.

\section{INDICADORES DO CURSO DE LETRAS: LICENCIATURA, UM PROBLEMA HISTÓRICO}

A proposição de mudança na estrutura conceitual-curricular do curso de Letras para fomentar o desenvolvimento de estudantes autônomos deve considerar o processo histórico de constituição do curso até os dias de hoje. Inicialmente, recorreremos a Saviani (2009) para contextualizar historicamente o início da formação de professores no Brasil até chegarmos à análise os cursos de Letras por Gatti (2009) e Paiva (2005).

Saviani (2009) relata que a preocupação em preparar pessoas para o magistério no Brasil iniciou no século XIX, após a declaração da independência, no embalo das ideias iluministas europeias de "levar a luz do conhecimento às classes populares", e organiza em seis períodos históricos a formação de professores: os ensaios intermitentes de formação de professores (1827-1890); o estabelecimento e a 
expansão do padrão das Escolas Normais (1890-1932); a organização dos Institutos de Educação (1932-1939); a organização e a implantação dos Cursos de Pedagogia e de Licenciatura e a consolidação das Escolas Normais (1939-1971); a substituição da Escola Normal pela Habilitação Específica de Magistério (1971-1996); e o advento dos Institutos Superiores de Educação, Escolas Normais Superiores e o novo perfil do Curso de Pedagogia (1996-2006).

$\mathrm{O}$ primeiro período objetivava formar professores para atuar nas escolas primárias e o currículo das Escolas Normais (instituições de ensino do magistério) concebia o professor como alguém que deveria saber o conteúdo a ser ministrado em sala, sem necessariamente ter um preparo didático-pedagógico na formação. Ainda nesse período, em 1849, houve uma tentativa do presidente da província do Rio de Janeiro, Couto Ferraz, de fechar as Escolas Normais (SAVIANI, 2009), por ser um investimento oneroso na relação custo-benefício, e instituir os professores adjuntos, que seriam formados enquanto ajudavam os professores regentes de sala. Esse modelo não se concretizou, as Escolas Normais continuaram se instalando e prosseguiram seu trabalho.

O segundo período foi marcado pela primeira tentativa de renovação das Escolas Normais. Capitaneado pela reforma educacional do estado de São Paulo, o novo modelo propunha "enriquecimento dos conteúdos curriculares anteriores e ênfase nos exercícios práticos" (SAVIANI, 2009, p. 143), sendo a instituição das escolas-modelo vinculadas às Escolas Normais (que nos remete aos atuais Colégios de Aplicação das IES) o passo mais significativo de inovação. Entretanto, os esforços reformadores não obtiveram o êxito esperado, pois ainda carregavam a "força do padrão dominante, centrado na preocupação com o domínio dos conhecimentos a serem transmitidos" (SAVIANI, 2009, p.145).

$\mathrm{O}$ terceiro período constitui-se em uma fase influenciada fortemente pelos ideais da Escola Nova ${ }^{3}$, em ações isoladas no Distrito Federal e em São Paulo, culminando na criação dos institutos de educação "concebidos como espaços de cultivo da educação, encarada não apenas como objeto do ensino mas também da pesquisa" (SAVIANI, 2009, p.145). A concepção escolanovista exigia uma estrutura centrada nas necessidades do estudante e buscava consolidar a pedagogia como campo científico, logo, enriqueceu-se consideravelmente o currículo para formar professores qualificados didática e pedagogicamente e investiu-se em espaços de apoio para pesquisa e prática, como a criação de escolas do jardim de infância ao

3 Saviani (1982) define a concepção pedagógica escolanovista como um contraponto ao ensino tradicional, pois centra suas ações no aprendizado e, para isso, investe em infraestrutura, preparação da equipe pedagógica multidisciplinar e docente para atender às necessidades individualizadas dos educandos. 
ensino secundário, institutos de pesquisa, bibliotecas central e escolar, filmotecas, museus escolares e radiodifusão (SAVIANI, 2009). Para situar historicamente, Fiorin (2006, p.15) relata que em meados da década de 1930 surgiram os primeiros cursos de Letras, os quais eram organizados "em dois cursos: Letras Clássicas e Português e Letras Estrangeiras". Os Institutos de Educação do Distrito Federal e de São Paulo obtiveram o reconhecimento de sua proposta pedagógica, seus cursos foram elevados ao nível universitário e sua base serviu de padrão para as demais graduações no país, endossado pelo decreto-lei n 1.190 , de 4 de abril de 1939, que também reorganizaria, utilizando o modelo carioca, os cursos de Letras em Clássicas, Neolatinas e Anglo-Germânicas (FIORIN, 2006). Poder-se-ia considerar que esse momento caracterizou-se como uma iniciativa concreta e sistematizada de promover o suporte para professores em formação desenvolverem a autonomia para poder, a partir de sua experiência aliada ao conhecimento teórico-metodológico, trabalhar a autonomia em sua futura sala de aula, mas...

O quarto período são os desdobramentos da promulgação do DecretoLei ${ }^{\circ} 1.190 / 1939$, cujo maior feito foi o advento do modelo conhecido como o " $3+1$ ": três anos de estudo dos conteúdos específicos das diversas disciplinas da EB e um ano para formação didática. Além dessa interpretação errônea do projeto pedagógico paulista/carioca no nível curricular, a generalização do modelo também não trouxe consigo as escolas experimentais, que serviam de campo de pesquisa para retroalimentar a formação dos licenciandos. A preparação pedagógica continuou sendo minada e o processo de consolidação de formação de professores centrados nos conhecimentos específicos, chamados por Saviani de "conteúdos culturaiscognitivos" (SAVIANI, 2009, p.147), acentuou-se com a dispensa da exigência das escolas-laboratório. Assim, fortaleceu-se a hierarquia de saberes docentes, elevando as especificidades ao topo e rebaixando o didático-pedagógico a "uma mera exigência formal para a obtenção do registro profissional de professor" (SAVIANI, 2009, p.147). Paiva (2003, p.13) avalia que "esse fosso que se estabeleceu entre disciplinas de conteúdo e disciplinas pedagógicas é um dos fatores que geram a precariedade da formação de professores de língua nos cursos de Letras no país". De 1962 a 1969, foram aprovadas normativas que ainda exercem influência sobre os projetos pedagógicos de Letras (PAIVA, 2003 e 2005), quais sejam: o Parecer CFE ${ }^{4}$ nº 283 de 19 de outubro de 1962 que fixou o currículo mínimo dos cursos de Letras, cuja resolução instituiu a habilitação dupla; a Portaria MEC nº 155 de 17 de maio de 1966, que delimitou as áreas de licenciatura plena em língua e literatura vernácula

4 Conselho Federal de Educação, nomenclatura anterior ao atual Conselho Nacional de Educação. 
e estrangeira (clássica ou estrangeira); a Resolução CFE $n^{\circ} 9$ de 10 de outubro de 1969, que fixou a carga horária mínima de $1 / 8$ das horas fixadas para a formação pedagógica, contemplando no artigo $1^{\mathrm{o}}$ as disciplinas de psicologia da educação, didática e estrutura e funcionamento de ensino de $2^{\circ}$ grau.

O quinto período situa-se entre a Lei ${ }^{\circ} 5.692 / 71$, a penúltima lei de diretrizes e bases da educação nacional, até as legislações que antecederam a atual LDB. O governo militar reordenou a educação nacional (renomeando os ensinos primário e médio para $1^{\circ}$ e $2^{\circ}$ grau, por exemplo) e, consequentemente, a preparação de professores para a escola continuou sem uma política coesa e dependente da conjuntura política, a qual, segundo Cacete (2011), seria feita: em escola de $2^{\circ}$ grau, para lecionar da $1^{\mathrm{a}}$ à $4^{\mathrm{a}}$ série do $1^{\mathrm{o}}$ grau; em curso superior de curta duração (licenciatura curta), para atuar da $5^{\mathrm{a}}$ à $8^{\mathrm{a}}$ série do $1^{\mathrm{o}}$ grau; em curso superior de longa duração (licenciatura plena), para trabalhar no $2^{\circ}$ grau. Saviani (2009) relata mais um elemento no processo de precarização do ensino brasileiro e das licenciaturas, em específico no curso de Pedagogia, que, após conquistar profissionalmente o patamar de ensino superior, recuou para suas origens no século XIX:

\footnotetext{
Pelo Parecer n. 349/72 (Brasil-MEC-CFE, 1972), aprovado em 6 de abril de 1972, a habilitação específica do magistério foi organizada em duas modalidades básicas: uma com duração de três anos (2.200 horas), que habilitaria a lecionar até a $4^{\mathrm{a}}$ série; e a outra com a duração de quatro anos (2.900 horas), habilitando ao magistério até a $6^{\text {a }}$ série do $1^{\circ}$ grau. O currículo mínimo compreendia o núcleo comum, obrigatório em todo o território nacional para todo o ensino de $1^{\circ}$ e $2^{\circ}$ graus, destinado a garantir a formação geral, e uma parte diversificada, visando à formação especial.
}

Progressivamente, vemos que as medidas legislativas dessa época consolidaram a formação massificada de professores, abdicando da qualidade e investindo no perfil polivalente. Se nos anos 1960 era para atender emergencialmente à crescente expansão das escolas secundárias iniciada na metade dos anos 1960, a partir dos anos 1970 tornar-se-ia regular, "ganhando inclusive uma justificativa pedagógica" (CACETE, 2011, p.25). O plano do governo era formar docentes por grandes campos de atuação para dar conta de várias áreas (como Ciências, que abrangia Matemática, Física, Química e Biologia) e depois, caso o professor optasse, fazer uma complementação de estudos de um ano em uma disciplina específica, como pode ser conferido na Indicação n²2/73 (CACETE, 2011, p. 25), aplicada aos cursos de Letras, segundo a qual

[u]m licenciado em Estudos Sociais com habilitação em Geografia [...] poderá simplesmente dizer-se diplomado em Geografia, como antes, porque de fato o será; mas terá outras vantagens. Em pouco tempo, às vezes menos de um ano, facilmente se habilitará também em História, ou Organização Social e Política do Brasil, ou em 
Educação Moral e Cívica - ou em todas essas disciplinas, mediante sucessivas voltas à escola.

A autora acrescenta (CACETE, 2011) que as faculdades de filosofia abandonaram os bacharelados e a dedicação à pesquisa científica para assumir um papel de polo de licenciatura (como vemos em muitas IES estaduais do Paraná, por exemplo), como se fosse possível abrir mão da indissociabilidade acadêmica ensino-pesquisa-extensão para fortalecer isoladamente uma das bases do tripé. Nesse cenário, as graduações em Letras se deparavam com o desafio de conduzir um curso de língua e literatura com carga horária reduzida, de baixo prestígio intelectual e social (afinal, não precisava estudar muito tempo para ensinar), defasado pedagogicamente e tendo que lidar - já sendo organizado historicamente como apêndice do bacharelado - com outros apêndices: as línguas estrangeiras. Sobre estas, Paiva (2003, p.18) expõe uma problemática que, infelizmente, continuamos a ver, ao afirmar que "a legislação nunca se preocupou com a formação do professor em LE e nunca definiu a porcentagem de horas que deveria ser destinada para essa formação". Mas, a partir dos anos de 1980, ocorre um amplo movimento de reformulação das licenciaturas e aumenta a expectativa pela sua valorização (SAVIANI, 2009), inspirado pela retomada do estado democrático de direito, a promulgação da Constituição Federal de 1988 e do Estatuto da Criança e do Adolescente (ECA). Seria esse o espírito da nova LDB? Não.

O sexto e atual período começa a partir da Lei 9.394/96 e é o resultado de uma política classificada como neoliberal ${ }^{5}$, cujo objetivo é desonerar o estado de suas responsabilidades com a população, reduzindo custos nos serviços públicos e alimentando o capital privado. Um dos resultados dessa política na educação foi a proliferação de instituições particulares que ofertam cursos de qualidade duvidosa. Para Saviani (2009, p.148 apud SAVIANI, 2008c, p.218-221):

(...) a LDB sinalizou para uma política educacional tendente a efetuar um nivelamento por baixo: os institutos superiores de educação emergem como instituições de nível superior de segunda categoria, provendo uma formação mais aligeirada, mais barata, por meio de cursos de curta duração.

\footnotetext{
5 Santos $(2005$, p.16) relata que o efeito da política neoliberal nas universidades públicas a partir da década de 1980 "significou que as debilidades institucionais identificadas (...) em vez de servirem de justificação a um vasto programa político-pedagógico de reforma da universidade pública, foram declaradas insuperáveis e utilizadas para justificar a abertura generalizada do bem público universitário à exploração comercial."
} 
$\mathrm{Na}$ esfera pedagógica, as formações de professores voltaram a investir nas especificidades (como o caso do antigo curso de Educação Artística, que passou da polivalência à divisão em Artes Cênicas, Artes Visuais, Música e Dança) - apesar de haver um movimento subliminar de retorno ao modelo da era militar concomitante à atual expansão das IES federais. O MEC publicou os Parâmetros Curriculares Nacionais (PCN) de cada disciplina com a concepção teórico-metodológica de ensino para a EB e, como dito anteriormente, o CNE exarou os Pareceres n ${ }^{\circ} 776 / 97$, $n^{\circ} 009 / 2001$ e n492/2001 para embasar a construção dos projetos pedagógicos da área de Letras, mas ainda não se obteve o resultado almejado. Primeiro, porque algumas instituições ainda "driblam" a legislação e não implementaram as normativas, em especial, "quanto à carga horária destinada às disciplinas de prática profissional" (ROMANOWSKI e MARTINS, 2010, p. 515). Segundo, porque seguir os documentos oficiais não garante qualidade. De acordo com Gatti (2009, p.77):

\begin{abstract}
A incorporação nos Projetos Pedagógicos de diretrizes oficiais não é garantia de que o processo educativo se realize segundo a filosofia que fundamenta sua elaboração. Assim, como não é determinante que uma instituição que não revele preocupação explícita com os PCN's ofereça formação específica de má qualidade. Por outro lado, cursos que expressam ostensivamente sua adesão às propostas oficiais podem revelar, à luz de uma investigação mais cuidadosa, componentes curriculares desintegrados, incoerências de vária ordem, o que nos faz levantar suspeita de que as diretrizes podem estar mais presentes no plano da retórica do que no da ação pedagógica.
\end{abstract}

O processo de precarização acentua-se quando consideramos que os cursos menos concorridos nas IES são os de licenciatura, gerando baixa concorrência e, portanto, sem medo de incorrer em juízo de valor ou preconceito (até porque nos enquadramos nessa situação), compondo um corpo discente com defasagem cultural, científica e teórica de base. Vide as tabelas abaixo:

Tabela 1. Relação candidato vaga dos cursos de graduação em Letras no vestibular 2011-2012/ Universidade Federal do Paraná (95 cursos de graduação ofertados)

\begin{tabular}{|l|l|c|c|c|}
\hline $\begin{array}{c}\text { Colocação dos } \\
\text { cursos de Letras na } \\
\text { concorrência à vaga }\end{array}$ & \multicolumn{1}{|c|}{ Curso } & Concorrentes & Vagas Disponíveis & $\begin{array}{c}\text { Candidato/ } \\
\text { Vaga }\end{array}$ \\
\hline $15^{\circ}$ & $\begin{array}{l}\text { Letras - Inglês ou } \\
\text { Português com Inglês } \\
-\mathrm{M}\end{array}$ & 191 & 18 & 10,61 \\
\hline $38^{\circ}$ & Letras - Inglês - N & 113 & 18 & 06,28 \\
\hline $62^{\circ}$ & Letras - Francês - N & 59 & 18 & 03,28 \\
\hline
\end{tabular}




\begin{tabular}{|l|l|c|c|c|}
\hline $65^{\circ}$ & Letras - Português - N & 115 & 36 & 03,19 \\
\hline $67^{\circ}$ & $\begin{array}{l}\text { Letras - Port. ou Alem. } \\
\text { ou Greg. ou Lat. } \\
\text { ou Port. +Alem. ou } \\
+ \text { Greg. ou + Lat. - M }\end{array}$ & 68 & 22 & 03,09 \\
\hline $73^{\circ}$ & $\begin{array}{l}\text { Letras - Espanhol } \\
\text { ou Português com } \\
\text { Espanhol - M }\end{array}$ & 65 & 22 & 02,95 \\
\hline $74^{\circ}$ & Letras - Japonês - N & 53 & 18 & 02,94 \\
\hline $83^{\circ}$ & $\begin{array}{l}\text { Letras - Italiano ou } \\
\text { Português com Italiano } \\
- \text { M }\end{array}$ & 32 & 13 & 02,46 \\
\hline $87^{\circ}$ & Letras - Polonês - N & 18 & 9 & 02,00 \\
\hline
\end{tabular}

Tabela 2. Relação candidato vaga dos cursos de graduação em Letras no vestibular 2011-2012/ Universidade Estadual de Londrina (66 cursos de graduação ofertados)

\begin{tabular}{|c|c|c|c|c|}
\hline $\begin{array}{c}\text { Colocação dos } \\
\text { cursos de Letras na } \\
\text { concorrência à vaga }\end{array}$ & Curso & Vagas & $\begin{array}{l}\text { Total de } \\
\text { candidatos }\end{array}$ & $\begin{array}{l}\text { Candidato/ } \\
\text { Vaga }\end{array}$ \\
\hline $38^{\circ}$ & $\begin{array}{l}\text { Letras - língua inglesa e } \\
\text { literaturas em língua inglesa } \\
\text { (noturno) }\end{array}$ & 20 & 63 & 4,58 \\
\hline $59^{\circ}$ & $\begin{array}{l}\text { Letras - língua inglesa e } \\
\text { literaturas em língua inglesa } \\
\text { (vespertino) }\end{array}$ & 20 & 33 & 2 \\
\hline $62^{\circ}$ & Letras (noturno) & 60 & 67 & 1,19 \\
\hline $63^{\circ}$ & $\begin{array}{l}\text { Letras - língua espanhola } \\
\text { e literatura hispânica } \\
\text { (noturno) }\end{array}$ & 20 & 22 & 1,17 \\
\hline $64^{\circ}$ & Letras (vespertino) & 60 & 65 & 1,14 \\
\hline $65^{\circ}$ & $\begin{array}{l}\text { Letras - língua e cultura } \\
\text { francesas (noturno) }\end{array}$ & 20 & 17 & 0,8 \\
\hline $66^{\circ}$ & $\begin{array}{l}\text { Letras - língua espanhola } \\
\text { e literatura hispânica } \\
\text { (vespertino) }\end{array}$ & 20 & 10 & 0,44 \\
\hline
\end{tabular}


Tabela 3. Relação candidato vaga dos cursos de graduação em Letras no vestibular 2011-2012/ Universidade Estadual do Oeste do Paraná

\begin{tabular}{|l|l|r|r|r|}
\hline $\begin{array}{c}\text { Colocação dos } \\
\text { cursos de Letras na } \\
\text { concorrência à vaga }\end{array}$ & Curso & Vagas & $\begin{array}{c}\text { Total de } \\
\text { candidatos }\end{array}$ & $\begin{array}{c}\text { Candidato/ } \\
\text { Vaga }\end{array}$ \\
\hline \multicolumn{5}{|c|}{ Campus Cascavel (19 cursos) } \\
\hline $09^{\circ}$ & Letras Português/Inglês & 20 & 81 & 4,05 \\
\hline $17^{\circ}$ & Letras Português/Espanhol & 15 & 35 & 2,33 \\
\hline $19^{\circ}$ & Letras Português/Italiano & 15 & 17 & 1,13 \\
\hline \multicolumn{7}{|c|}{ Campus Foz do Iguaçu (13 cursos) } \\
\hline $10^{\circ}$ & Letras Português/Inglês & 22 & 50 & 1,91 \\
\hline $11^{\circ}$ & Letras Português/Espanhol & 22 & 42 \\
\hline \multicolumn{7}{|c|}{ Campus Marechal Cândido Rondon (13 cursos) } \\
\hline $07^{\circ}$ & Letras Português/Inglês & 15 & 40 & 2,67 \\
\hline $08^{\circ}$ & Letras Português/Espanhol & 15 & 36 & 2,40 \\
\hline $13^{\circ}$ & Letras Português/Alemão & 10 & 7 & 0,70 \\
\hline
\end{tabular}

De acordo com o levantamento de Gatti (2010), quase metade dos estudantes vêm de famílias com escolaridade até as séries iniciais do EF e 68,4\% frequentaram todo o EM na preocupante escola pública ${ }^{6}$. Além da baixa competição pelas vagas, o perfil do estudante que ingressa na formação de professores são, na maioria (GATTI, 2010): trabalhadores em período integral $(43,3 \%)$ ou parcial $(20,1 \%)$; informam-se principalmente pela televisão $(58,3 \%)$; quase metade não visa o magistério ou o quer como alternativa profissional (21\%). Ao abordar o problema da inserção de disciplinas de língua portuguesa (LP) nas licenciaturas de língua e literatura estrangeira (LE), Paiva (2003, p.14) diagnostica o seguinte quadro que pode ser aplicado a vários outros cursos:

Assim, sob o pretexto da supremacia do idioma materno, não se permite um ensino de qualidade de LE, alimentando o círculo vicioso: os Cursos de Letras não formam bons professores, esses professores não têm a competência necessária para ensinar a língua, o ensino básico não oferece um ensino de LE de qualidade e seus egressos procuram

6 Segundo dados de 2009 do Instituto Nacional de Estudos e Pesquisas Educacionais Anísio Teixeira (INEP) sobre o Exame Nacional do Ensino Médio (ENEM), a média dos estudantes oriundos da escola pública na prova objetiva atingiu 39,59 pontos e na redação 58,61 de 100 possíveis. No Paraná, as respectivas médias são 41, 53 e 58,07. Segundo os critérios da instituição avaliadora, as notas no intervalo entre 0 e 40 pontos correspondem a desempenho insuficiente a regular na prova objetiva e entre 40,01 a 70 são considerados de regular a bom na redação. 
o curso de Letras para se transformarem em professores no prazo de três anos. (grifos nossos)

Bagno (2008) avalia a situação dos cursos de LP na mesma perspectiva tanto no que diz respeito ao corpo discente ingressante quanto a sua inserção nas salas de aula, as quais "já estão ocupadas, neste momento, por essas pessoas, de quem se cobra tanto e a quem não se oferece uma formação docente que também seja, minimamente, decente". Podemos concluir que o curso de Letras enquadra-se na expressão "crise das licenciaturas"? Arriscamos dizer que sim. É possível atender ao princípio das diretrizes de Letras (MEC/CNE/CES, 200, p.29) de dar "prioridade à abordagem pedagógica centrada no desenvolvimento da autonomia do aluno" apesar do quadro apresentado? $\mathrm{Na}$ atual conjuntura, pouco provável. Contudo, Gatti (2010), Bagno (2008), Saviani (2009) e Paiva (2003) apontam um caminho possível (e necessário) para mudar o status quo: mexer criticamente na estrutura conceitual do Projeto Pedagógico. É um processo complexo que exige investimento e gera desconforto, angústia e insegurança, tal como será relatado a seguir.

\section{NO PAIN, NO GAIN}

A construção de um projeto pedagógico flexível que atente às questões sociais (MASETTO, 2011), foque suas ações no desenvolvimento da autonomia dos estudantes e considere suas capacidades e limitações ainda é uma meta longínqua nos cursos de Letras (e por que não nas demais licenciaturas?) pelo histórico problemático que trouxemos anteriormente. Em contraponto à herança curricular de décadas, Masetto (2011, p.5) adiciona mais alguns elementos ao que se espera da educação na atualidade:

\footnotetext{
A organização de um currículo também coloca seus construtores numa perspectiva de perscrutar o borizonte em busca de novas possibilidades, de desafiar os limites do estabelecido e pensar um ensino superior que responda às exigências atuais e futuras. Permite ainda que se possa propor um projeto educacional para a formação de profissionais que estejam voltados para a transformação da ordem social, em benefício de melhores condições de vida para as populações. (grifos nossos)
}

A pergunta que paira no ar é: o que falta para chegarmos próximo de uma formação de professores ideal? O respaldo legal existe, vide a introdução às diretrizes do curso de Letras (MEC/CNE/CP, Parecer 492/2001, p.29) que compactua (com uma década de antecedência) com Masetto nos seguintes termos: 


\begin{abstract}
Esta proposta de Diretrizes Curriculares leva em consideração os desafios da educação superior diante das intensas transformações que têm ocorrido na sociedade contemporânea, no mercado de trabalho e nas condições de exercício profissional. Concebe-se a Universidade não apenas como produtora e detentora do conhecimento e do saber, mas, também, como instância voltada para atender às necessidades educativas e tecnológicas da sociedade. Ressalta-se, no entanto, que a Universidade não pode ser vista apenas como instância reflexa da sociedade e do mundo do trabalho. Ela deve ser um espaço de cultura e de imaginação criativa, capaz de intervir na sociedade, transformando-a em termos éticos. (grifos nossos)
\end{abstract}

Ousamos afirmar que falta atitude para promover mudanças realmente inovadoras, pois mudanças para manter as coisas como estão abundam no meio universitário. Para Cunha (2003, p.150), a inovação é "entendida como ruptura paradigmática" e "agir contra um modelo político que impõe, não raras vezes, a homogeneização como paradigma". Assim, teríamos que avaliar as consequências de um movimento de sair da zona de conforto. Estaríamos prontos para, como diria Jordão (2006, p.1), "identificar e desafiar constantemente nossos pressupostos e implicações"? No Brasil, há vários casos de IES que implantaram propostas pedagógicas inovadoras que fluíram, ao que parece, porque tiveram respaldo institucional e adesão coletiva do corpo docente (MASETTO, 2011). Entretanto, essas experiências ainda são iniciativas insulares, provavelmente pelo alto grau de comprometimento e doação (intelectual, psicológica e emocional) requisitados para o desafio. É preciso, também, empoderar os discentes nos processos decisórios e fazê-los, em assembleias gerais com o corpo docente, colocarem abertamente as potencialidades e fragilidades do curso, de modo a fazer do PPC uma construção realmente coletiva sinérgica, não um amontoado de concessões a indivíduos para amenizar problemas políticos ou satisfazer egos, o que poderia contribuir para sair da lógica disciplinar e organizar um curso a partir de seus objetivos gerais. As avaliações institucionais internas devem ser melhoradas progressivamente e transformadas em instrumentos de ações efetivas, como investimento em formação continuada para os professores (desde que seja por estes propostas, senão não haverá adesão), melhoria de oferta de estrutura (laboratórios, acervo bibliográfico) e parâmetro para planejamento de longo prazo, em que possam ser observados os avanços conquistados. A intensificação do diálogo com a comunidade externa é outra variável relevante, pois a baixa procura da licenciatura em Letras, em algumas habilitações específicas em certas regiões, pode indicar que não houve uma pesquisa de demanda que justificasse a abertura do curso e uma baixa articulação com a comunidade atendida no nível estratégico.

Em uma perspectiva exógena, é necessária uma ampla mobilização política para protagonizar os processos decisórios normativos para Letras junto ao MEC/ 
CNE e valorizar a carreira profissional docente, a fim de torná-la mais atrativa e superar as ideias de que ser professor é um dom inato e de que é vantagem poder tirar férias duas vezes por ano. Se a licenciatura ambiciona a mesma valorização de outras profissões, é preciso fazer valer sua força, por ser um formador de opinião e ter um contingente de massa. Contudo, a greve das universidades federais demonstrou explicitamente o quadro atual de valorização dos professores: enquanto estes precisaram de quase quatro meses para obter alguns resultados, considerando o nível de exigência acadêmico de titulação e produção científica para ascensão na carreira, outros setores do executivo, com metas produtivas mais brandas, conseguiram reajustes salariais equivalentes de forma menos desgastante publicamente. Assim, embora as reivindicações da classe e a precariedade de condições no ensino superior tenham ganhado visibilidade, é preciso um trabalho intenso, a começar pela educação básica, para transformar o magistério em um objetivo profissional desejável e compensatório de longo prazo, que qualifique o perfil discente ingressante e este provoque as IES a buscarem a excelência, constituindo um círculo virtuoso.

\section{RESUMO DA ÓPERA}

O plano de formar professores autônomos passa necessariamente pelo corpo docente responsável pelo curso - cujo papel é contrariar a lógica política e pedagógica descrita no histórico apresentado neste trabalho - e pelos outros atores anteriormente citados. Pesquisas e publicações para estudo não faltam, fartam. Paiva (2004) destaca a importância da flexibilização da legislação para a mudança no perfil do curso de Letras, a qual já oferece amparo para promover inovações, mas ao mesmo tempo alerta que o tradicionalismo e o medo do novo, motivado pelo preconceito, ainda são barreiras para efetivar transformações. Por isso, as conquistas serão diretamente proporcionais ao engajamento pela causa. Se o presente trabalho tem limitações em apontar soluções, minimamente pretende pautar a responsabilidade dos formadores de professores de línguas e respectivos estudantes a discutir conjuntamente uma agenda de trabalho e mobilização em prol do presente e do futuro da profissão. 


\section{REFERÊNCIAS BIBLIOGRÁFICAS}

BAGNO, M. (2008). A catástrofe dos cursos de Letras. Publicado originalmente na Revista Caros Amigos, nov. Disponível em: $<$ http://marcosbagno.com.br/site/?page $\mathrm{id}=464>$ Acessado em 28/08/2012.

BENSON, P. (2006). Autonomy in language teaching and learninig. Cambridge: Cambridge University Press, 2006. p. 21-40.

BRASIL. (1996). Lei 9.394/96 de 20 de dezembro de 1996. Estabelece as diretrizes e bases da educação nacional. Diário Oficial [da] República Federativa do Brasil. Brasília, DF, 23 de dez. 1996. Disponível em: < http://www.planalto.gov.br/ccivil_03/Leis/ L9394.htm > . Acesso em: 30 de agosto de 2012.

(1997). Conselho Nacional de Educação / Câmara de Educação Superior. Orientação para as diretrizes curriculares dos cursos de graduação. Parecer n ${ }^{\circ} 776$ de 3 de dezembro de 1997. Disponível em: <http://portal.mec.gov.br/cne/arquivos/ pdf/CES0776.pdf>. Acesso em: 26 de agosto de 2012.

(2001). Conselho Nacional de Educação / Câmara de Educação Superior. Diretrizes Curriculares Nacionais dos cursos de Filosofia, História, Geografia, Serviço Social, Comunicação Social, Ciências Sociais, Letras, Biblioteconomia, Arquivologia e Museologia. Parecer n ${ }^{\circ} 492$ de 3 de abril de 2001. Disponível em: $<$ http://portal.mec.gov.br/cne/arquivos/pdf/CES0492.pdf.> Acesso em: 14 de agosto de 2012

(2001). Conselho Nacional de Educação/ Câmara de Educação Superior. Orientação para as diretrizes curriculares dos cursos de graduação. Parecer n583/2001 de 4 de abril de 2001. Disponível em: <http://portal.mec.gov.br/index. php? option $=$ com_docman\&task $=$ doc_download\&gid $=6545 \&$ Itemid $=>$ Acesso em: 12 de agosto de 2012.

(2001). Conselho Nacional de Educação / Conselho Pleno. Diretrizes Curriculares Nacionais para a Formação de Professores da Educação Básica, em nível superior, curso de licenciatura, graduação plena. Parecer n ${ }^{\circ} 09$ de 8 de maio de 2001. Disponível em: <http://portal.mec.gov.br/cne/arquivos/pdf/009.pdf.> Acesso em: 15 de agosto de 2012.

(2002). Conselho Nacional de Educação/ Conselho Pleno. Institui Diretrizes Curriculares Nacionais para a Formação de Professores da Educação Básica, em nível superior, curso de licenciatura, de graduação plena. Resolução n $01 / 2002$ de 18 de fevereiro de 2002. Disponível em: < http://portal.mec.gov.br/cne/arquivos/pdf/ rcp01_02.pdf.> Acesso em: 14 de agosto de 2012.

(2011). Conselho Nacional de Educação / Conselho Pleno. Estabelece diretrizes para a obtenção de uma nova habilitação pelos portadores de Diploma de Licenciatura em Letras. Resolução nº1 de 18 de março de 2011. Disponível em: $\quad<$ http://download.inep.gov.br/educacao_superior/censo_superior/encontro_ 
nacional/2012/0911_resultados_censo_educacao_superior_2010.ppt > Acesso em: 14 de agosto de 2012.

BRASIL. (2009). Ministério da Educação. Instituto Nacional de Estudos e Pesquisas Educacionais Anísio Teixeira. Relatório pedagógico ENEM 2008. Brasília: INEP, jun. Disponível em: <http://download.inep.gov.br/educacao_basica/enem/relatorios pedagogicos/relatorio_pedagogico_enem_2008.pdf.> Acessado em: 24 de agosto de 2012.

CACETE, N.H. (2011). A evolução do ensino superior brasileiro e a formação de professores de geografia. Costa Rica: Revista Geográfica de América Central Número Especial EGAL, $2^{\circ}$ sem., p.01-33.

CHITASHVILI, N. (2007). The concept of autonomy in second language learning. Georgian Eletronic Scientific Journal: Education, Science and Psychology, n.2 (11), p.17-22.

CUNHA, M.I. (2003). Inovações pedagógicas: tempos de silêncios e possibilidades de produção. Revista Interface - Comunicação, Saúde e Educação, v.7, n.13, ago. , p.149-151.

FIORIN, J.L. (2006). A criação dos cursos de Letras no Brasil e as primeiras orientações da pesquisa linguística universitária. Revista Línguas e Letras, v.7, n²12, I sem. , p.11-25.

FONTANA, N.M. (2009). Construção da autonomia na formação de professores de língua estrangeira. In: SILVA, C.L.C. [et al]. Teorias do discurso e ensino [recurso eletrônico]. Porto Alegre: EDIPUCRS, p.175-210.

GATTI, B.A. (2010). Licenciaturas: crise sem mudança? In: DALBEN, A.I.L.F. et al (org.) Convergências e tensões no campo da formação docente. Belo Horizonte: Autêntica, p.485-508.

GATTI. B.A e NUNES, M.M.R. (org.). (2009). Formação de professores para o ensino fundamental: estudo de currículos das licenciaturas em pedagogia, língua portuguesa, matemática e ciências biológicas. São Paulo: FCC/DPE, p. 57-91/151-154.

JORDÃO, C. M. (2006). O Ensino de Línguas Estrangeiras - de código a discurso. In: VAZ BONI, Valéria. (Org.). Tendências Contemporâneas no Ensino de Línguas. União da Vitória: Kaygangue, v. , p.

LEFFA, V.J. (2003). Quando menos é mais: a autonomia na aprendizagem de línguas. In: NICOLAIDES, C.; MOZZILlO, I.; PACHALSKI, L.; MACHADO, M.; FERNANDES, V. (Org.). O desenvolvimento da autonomia no ambiente de aprendizagem de linguas estrangeiras. Pelotas: UFPEL, v., p.33-49.

MASETTO, M.T. (2011) Inovação curricular no ensino superior. São Paulo: Revista e-curriculum, São Paulo. v.7, n.2, ago.

(2003 -2004). Inovação na educação superior. Revista Interface - Comunicação, Saúde e Educação, v. 8, n.14, set.-fev.

PAIVA, V.L.M.O. (2003). A LDB e a legislação vigente sobre o ensino e a formação de professor de língua inglesa. In: STEVENS, C.M.T e CUNHA, M.J. Caminhos e Colbeitas: ensino e pesquisa na área de inglês no Brasil. Brasília: UnB, p.53- 84. Disponível em: $<$ http://www.veramenezes.com/publicacoes.html> (Acessado em 15/08/2012). 
PAIVA, V.L.M.O. (2004). Avaliação dos cursos de Letras e a formação do professor. Revista do GELNE. João Pessoa. Vol. 5, n. 1 e 2. p. 193-200. Disponível em: < http://www. veramenezes.com/publicacoes.html> (Acessado em 15/08/2012).

. (2005). O Novo Perfil dos Cursos de Licenciatura em Letras. In: TOMICH, et (Orgs.). A interculturalidade no ensino de inglês. Florianópolis: UFSC, p.345-363 (Advanced Research English Series). Disponível em: <http://www.veramenezes. com/publicacoes.html> (Acessado em 15/08/2012).

RODRIGUES, B.G. (2007). Formação de professores de língua inglesa em um curso de letras com babilitação única em inglês. Tese de doutorado em Linguística Aplicada e Estudos da Linguagem. PUC/SP, São Paulo.

ROMANOWSKI, J.P. e MARTINS, P.L.O. (2010). Situação atual das licenciaturas o que indicam as pesquisas a partir de 2000. In: DALBEN, A.I.L.F. et al (org.) Convergências e tensões no campo da formação docente. Belo Horizonte: Autêntica, p. 509-526.

SAVIANI, D. (1982). As teorias da educação e o problema da marginalidade na América Latina. São Paulo: ago., Cad. de Pesq., vol.42, p.8-18.

(2009). Formação de professores: aspectos históricos e teóricos do problema no contexto brasileiro. Revista Brasileira de Educação, v.14, n.40, jan./abr., p. 143-155.

SANTOS, B.S. (2005) A universidade no século XXI: para uma reforma democrática e emancipatória da universidade. São Paulo: Cortez, 2ed.

SMITH, R.C. (s/d). Teacher education for teacher autonomy. Warwick, UK: University of Warwick. Disponível em: <http://homepages.warwick.ac.uk/ elsdr/Teacher_ autonomy.pdf $>$ (Acessado em 04/05/2012).

UNIVERSIDADE ESTADUAL DE LONDRINA. Relação candidato/vaga do vestibular 2011-2012. Disponível em: <http://www.cops.uel.br/vestibular/2012/candidato_ vaga.pdf $>$ (Acessado em 28/08/2012).

UNIVERSIDADE ESTADUAL DO OESTE DO PARANÁ. Relação candidato/vaga do vestibular 2011-2012. Disponível em: < http://cac-php.unioeste.br/cogeps/ arquivos/vestibular/2012/CandidatoPorVaga.pdf> (Acessado em 28/08/2012)

UNIVERSIDADE FEDERAL DO PARANÁ. Relação candidato/vaga do vestibular 2011 2012. Disponível em: < http://www.nc.ufpr.br/>. (Acessado em 28/08/2012)

Recebido: 10/05/2012

Aceito: 24/03/2013 